\title{
SPINA BIFIDA AND ITS ASSOCIATED SKULL DEFECTS
}

\author{
BY \\ J. BLAIR HARTLEY, M.B., B.S., F.F.R., D.M.R.E. \\ Honorary Radiologist, Christie Hospital and Holt Radium Institute, Manchester \\ AND \\ C. W. F. BURNETT, M.D., M.R.C.O.G. \\ Resident Obstetrical Officer, Stepping Hill Hospital, Stockport
}

Some degree of interest has recently been aroused in the question of the occurrence and incidence of spina bifida. Despite the efforts made by many theorists in the past, its mode of production still remains obscure; it is known that fundamentally there is a defective formation of the mesodermal tissues surrounding the primitive neural plate, and that the process of chondrification and subsequent ossification of the early membranous spinal column may lead to the production of a minor fault such as spina bifida occulta, or to a major fault such as myelocele, meningocele, myelomeningocele, or syringocele, but the reasons why this defective development should be brought about are not known.

Earliest opinions ascribed it to supernatural happenings and maternal impressions, a view which lingered on until 1857 when it was mentioned by Wertheim in his report of a case. The first scientific theory was due to Morgagni, and quoted by Alexander in 1769. He suggested that there occurred an increased pressure of the cerebrospinal fluid, which prevented closure and union of the vertebral laminae, and also gave rise to the frequently associated hydrocephalus. This was disproved by Koch (1881), who pointed out that the pressure of the cerebro-spinal fluid could not exceed that of the surrounding liquor amnii, and also by the London Clinical Society, who appointed a committee to investigate the subject in 1885 , which demonstrated that general dilatation of the central canal did not occur as would be expected if the pressure were increased. Other observers considered that there existed a mechanical interference with the nutrition and development of the mesoblast of the spinal region, though they could not agree as to its nature.

St. Hilaire in the early part of the nineteenth century, and Dareste (1882) considered that amniotic adhesions were responsible, but Mall (1905) pointed out that spina bifida was of frequent occurrence in amphibia in whom no amnion is present. Lebedeff (1881) suggested that different parts of the embryo might grow at different rates, thereby producing abnormal curvatures and kinking of the embryonic spine, which might result in maldevelopment of the mesoblast. Similarly, Von Recklinghausen (1886) suggested that there was a primary aplasia of the skeletal axis resulting in the length of the cord exceeding that of the spine, which accommodated itself in the limited space by the process of bending, and so produced a spina bifida. Richter (1888) was able to produce experimental spina bifida by maintaining chick embryos at varying temperatures, thereby proving that external influences could affect the mesodermal development, whilst Morgan and 'Tsuda (1894) also demonstrated this by immersing frog's eggs in 0.6 per cent. saline. Bland Sutton (1888), by analogy with associated alimentary tract defects, suggested that the cord was a highly differentiated section of the gut, and as an obsolete canal was, therefore, prone to cystic dilatation. Cumston (1903) stated that syphilis was an important cause. Ballantyne (1902) considered that a germinal theory was the correct one, in view of the repeated occurrence of spina bifida in known families and also in twins. The committee of the London Clinical Society also favoured this view.

Good (1910), after an excellent review of past theories, came to the conclusion that in these cases there was an arrested development of the mesodermal tissues from which the spinal meninges were produced, caused by a mechanical agent of unknown nature. Observers now seem to be agreed upon the defective development of the mesoderm, but the main question whether this be due to germinal and hereditary causes, or to an external influence is still unsettled. Fry (1943), in a recent memorandum, reported two cases of spina bifida occurring in binovular twins, and concluded that the cause was basically a developmental anomaly not due to a mechanical agent nor to an external influence.

The majority of cases of spina bifida appear sporadically in apparently healthy individuals and families, but some examples are recorded in which the features of a familial incidence can be discerned. Butler-Smythe (1889) recorded a family of five, in which three children suffered from spina bifida associated with hydrocephalus, whilst the remaining two had hydrocephalus alone. Pybus (1921) described a family of four children who exhibited respectively spina bifida and hydrocephalus, spina bifida occulta, lumbo-sacral meningomyelocele, and a large coccygeal dimple, whilst there has recently 
been recorded a family of seven children of whom five were afflicted with the defect. These instances in the literature are rare. and yet when they do occur they do not appear to be the result of mere coincidence.

Attempts to ascertain the hereditary features of this anomaly have in the past yielded few results. This is largely due to the fact that cases exhibiting spina bifida rarely live and rarely reproduce, so that the defect has not the opportunity to be handed down from parent to child. The few cases that do have offspring are merely the cases of spina bifida occulta and the rare cases of successful operation that live on to adulthood, and when their children are born their original defect is not known, or is overlooked, and the hereditary incidence, if any, is not observed. Owing to the paucity of such cases and the number of years that must elapse prior to parenthood, the laws governing the inheritance of spina bifida are not likely to be elucidated by research directed along these channels. Similarly, the examination of the parents and siblings of known cases of spina bifida only rarely produces evidence of other related cases, and has provided insufficient material for the formulation of laws of heredity. It is apparent that if these laws are to be discovered, some other method in which more frequent and non-fatal examples abound will be more conducive to success.

\section{Skull defects}

This alternative method is provided by the study of the skull defects which may occur in association with spina bifida. These defects, presently to be described, are caused by a process analogous to that which causes spina bifida, and so may provide a clue to its mode of formation: moreover they occur more frequently than spina bifida, at an actual rate of 0.94 per cent. of all births, and they may occur in normal individuals, so that they provide much more material for the study of their inheritance.

These defects, which promise so much, are the maldevelopments of the cranial vault bones, which we have recently named craniolacunia and craniofenestria (1943a). These conditions were originally described in this country by West (1875), but they have since been overlooked. Thus Pybus (1921) in his report, gives a list of congenital malformations associated with spina bifida, but makes no mention of the cranial vault bones. Good (1910) devotes six pages to descriptions of associated defects, but does not include these anomalies, although he refers to rarer ones, such as splitting and complete absence of the occipital bone; whilst Fry (1943) makes no mention of any associated skull defects.

These conditions occur most frequently in cases of spina bifida, but are also encountered in association with hydrocephalus, craniostenosis, encephalocele, talipes, defective rib formation, and maldevelopment of the face, as well as in otherwise normal cases. In the same manner as spina bifida, they occur in mesoderm surrounding nervous

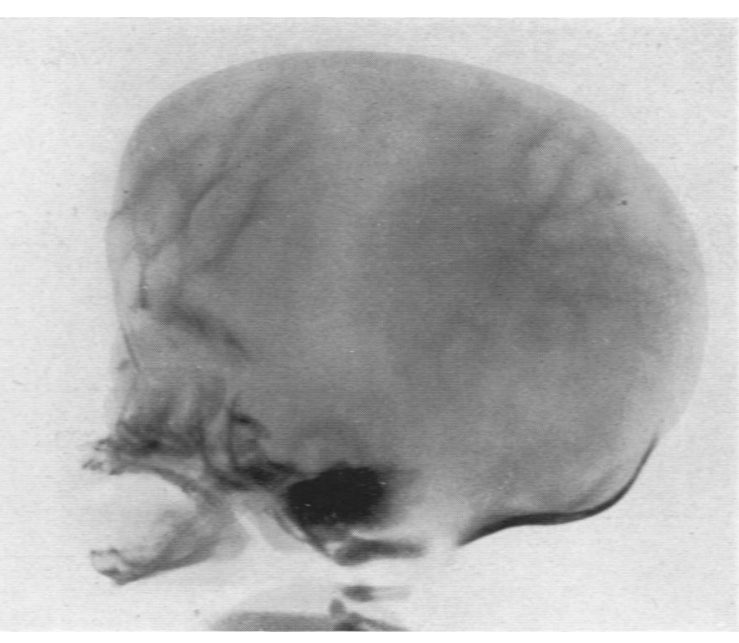

Fig. 1.-Radiograph of skull at birth showing craniolacunia.

tissue and affect these cranial vault bones, which are developed from membrane. Craniolacunia consists of an irregular ossification of the inner surfaces of the bones whereby thick bony bars or ridges are produced, which branch and unite in such a way as to form a reticulated pattern of circles and ellipses. In between the bars exist thinned areas of bone, which form the lacunae from which the condition is named (fig. 1, 3 and 4). In craniofenestria the defective ossification is carried a stage further, and areas marked by absent bone formation occur between the bars, so producing a pattern of fenestration (fig. 2, 5 and 6). In craniolacunia the outer surfaces of the bones are normal, as they are also in craniofenestria between the actual areas of absence of bone formation. The bones affected may be the frontals, parietals, great wings of the sphenoid, squamous temporals and the squamous occipital, and the deposition of bony tissue may be so deficient as to reduce the weight of the bones by

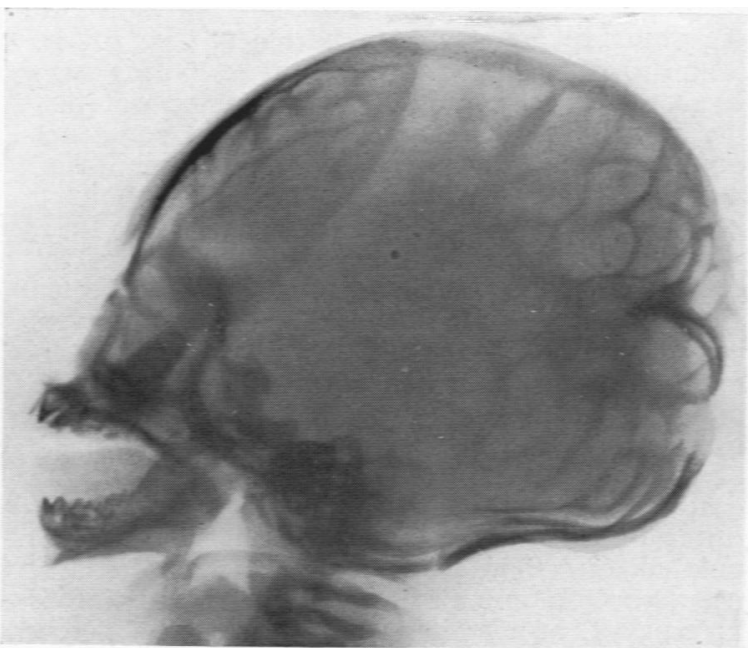

FIG. 2.-Radiograph of skull at birth showing craniofenestria. 


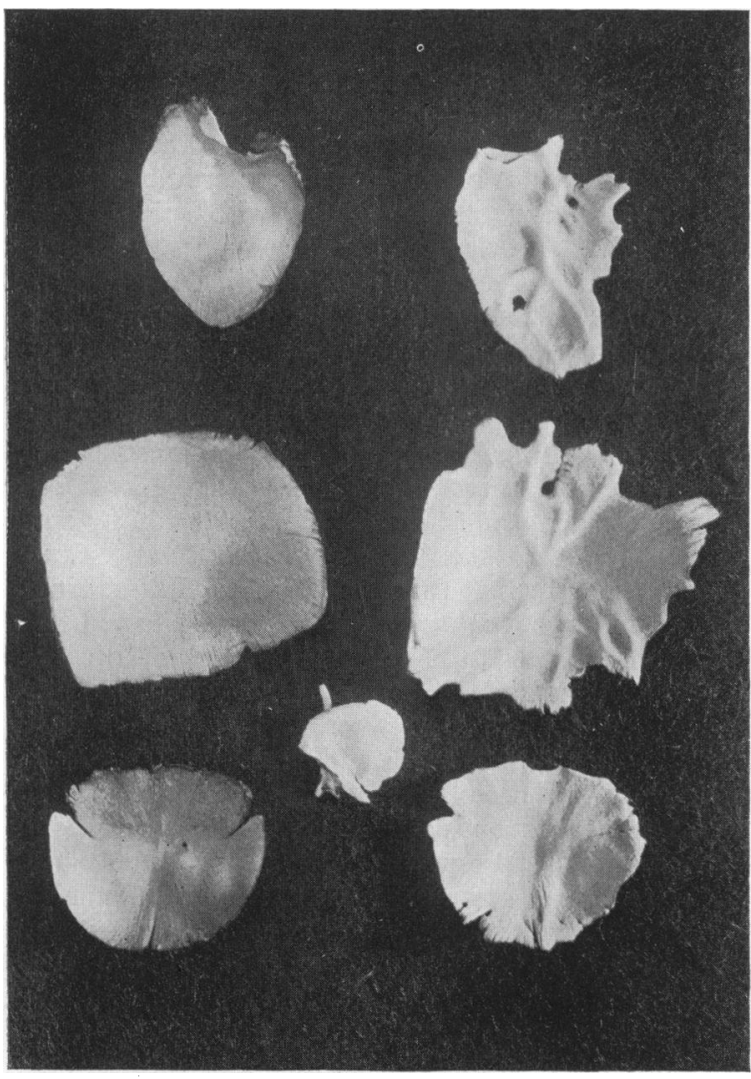

Fig. 3.-Photograph of dried vault bones showing craniolacunia alongside those of a normal foetus of the same age.

70 per cent. Further points of interest in the anatomy of these conditions are shown by the edges of the bones, which instead of being regular and finely curved, are deeply indented and tortuous (fig. 3 and 5). The bony bars themselves may be of great thickness, exceeding the thickness of the normal skull of the same age. The architecture of the bones is also distorted, for instead of a finely radiating trabeculation, from an eccentric focus in the bone to the periphery, the osseous pattern is completely promiscuous (fig. 4 and 6).

The features of craniolacunia and of craniofenestria which are of course well seen in the dried disarticulated bones themselves are equally well demonstrated radiologically, and as we have shown elsewhere, (1943b) these two conditions can be recognized from x-ray examination in utero, after birth, and in the growing child. On antenatal radiographs evidence of defective ossification of the vault is looked for, this being indicated by abnormality of outline, consisting of faults, thinning, or reduplication in otherwise normal skulls. The existence of hydramnios or hydrocephalus, although not of diagnostic significance is a warning to the radiologist to examine the outline of the vault in great detail for evidence of these defects.

When detected in antenatal radiographs, together with a spinal defect or deformity (fig. 7), or associated with evidence of craniostenosis, the findings are pathognomonic of craniolacunia or craniofenestria, although it is not always possible to distinguish between these two whilst the foetus remains in utero: much depends on the size of the mother.

At birth the defective outline of the vault will be confirmed radiologically. In craniolacunia there will be no projections beyond the margin of the vault, whilst the bars forming the coarsely reticulate pattern will be observed to be broad, and fading smoothly into the lacunar or thinned areas enclosed between them (fig. 1).

In the more striking condition of craniofenestria there may be projections visible beyond the outline of the vault. These are pathognomonic of fenestration. The pattern formed by the bars is here much greater in contrast, for the bars are thinner and of sharper outline, the transition from them to the areas of absence of ossification (fenestrae) being abrupt (fig. 2).

These appearances will be encountered irrespective of the size or shape of the infant's skull, or of hydrocephalus, extreme degrees of craniofenestria occurring in microcephalic, grossly hydrocephalic, or normal sized skulls, in all of which types one will see examples also of the mildest forms of craniolacunia.

Where it is possible to examine the dried vault bones, these findings can be confirmed and studied in greater detail. The bones may be photographed and kept for comparison with normals of the same stage of development: they may be weighed,

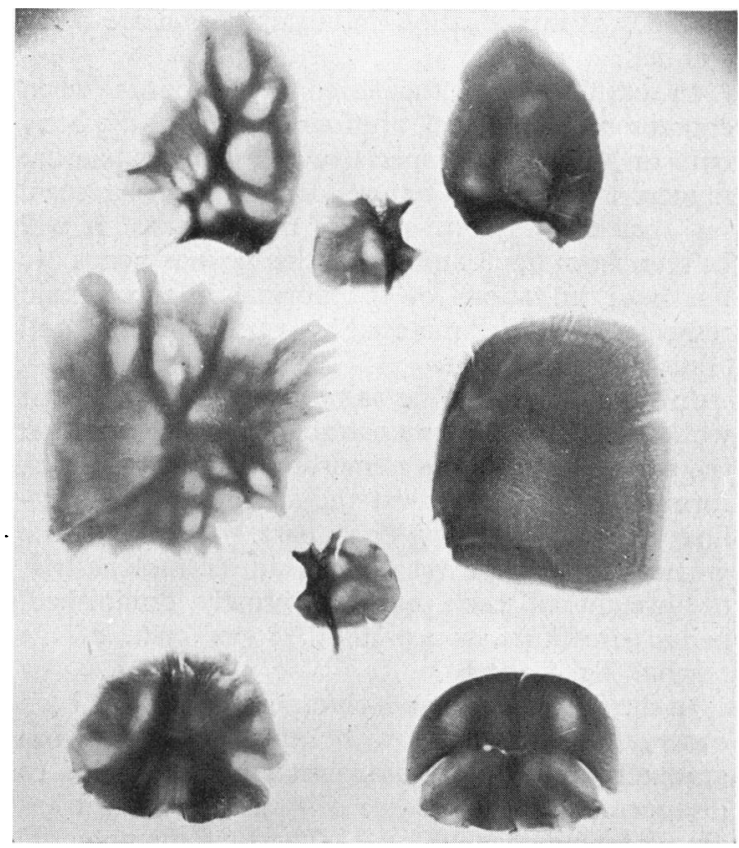

FIG. 4.-Radiograph of the same craniolacunar and normal bones revealing the poor texture, as well as the defective outlines in craniolacunia. 


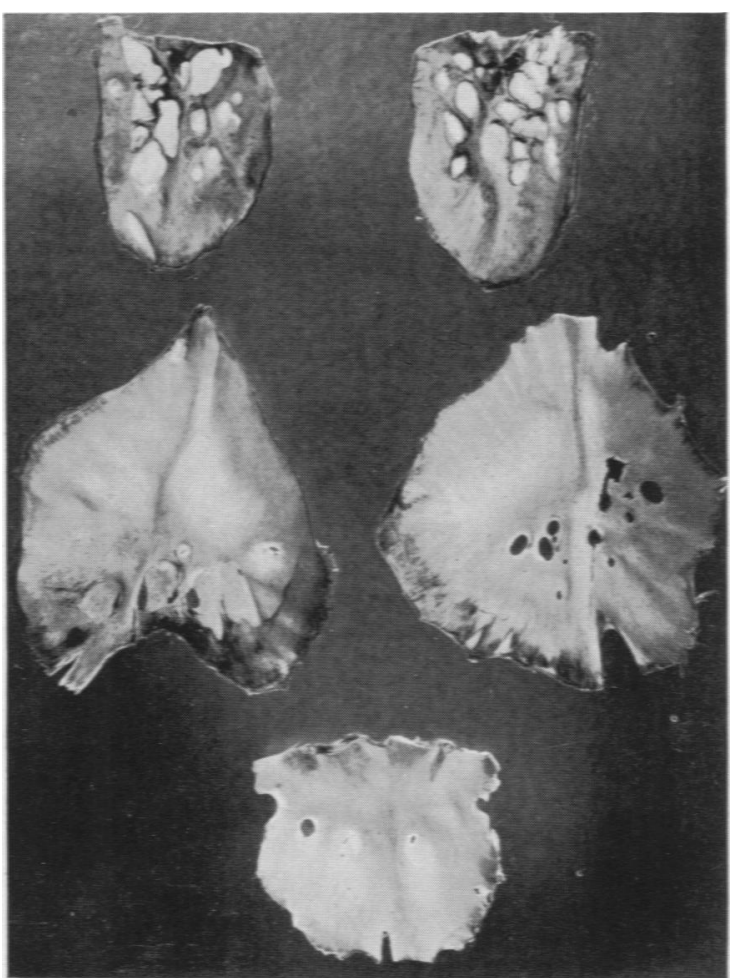

FIG. 5.-Photograph of dried hydrocephalic vault bones showing craniofenestria. The membranous covering of the fenestrae is clearly seen.

radiographed or sectioned; each process gradually building up the sum of knowledge, whilst new methods of investigation and examination are being planned.

In craniolacunia the dried vault bones when compared with normal, are found to reveal the bony bars on their inner aspects, whilst the lacunae are numerous. Isolated actual defects may be seen, but they do not form part of the pattern. It will be seen from fig. 3 and 4 that the lacunar bones are but poor imitations of the normal in three main respects, namely, 'material ', 'workmanship' and ' finish'.

In craniofenestria the same suggestion of 'poor workmanship' is demonstrable, but in addition there will be seen the numerous complete defects, forming a pattern against the sharply defined outlines of the intervening bony bars. In spite of the greater density of these bars in craniofenestria, the weight of each bone is grossly diminished, being sometimes as low as 22.8 per cent. of the normal (fig. 5 and 6).

In the few infants in which craniolacunia has been observed unassociated with other defects, it has gradually become less apparent and has tended to disappear with the passage of time, although it has always remained identifiable. These are the potential parents who may give birth to offspring with craniolacunia and spina bifida; if the skulls of the parents and relatives of known cases of spina bifida are $\mathbf{x}$-rayed, evidence of residual craniolacunia of this type may be found.

\section{Theories of origin}

Many theories have been adduced to account for the occurrence of craniolacunia and craniofenestria, and their frequent association with spina bifida. Mechanical theories were largely suggested, chiefly by German observers, some of which were highly ingenious. Thus Kassowitz (1880) considered that external pressure on the vault bones during birth was the cause of the maldevelopment; Von Recklinghausen (1886) suggested the presence of an internal hydrocephalus which compressed the cerebral gyri against the bones with the resultant formation of lacunae and fenestrae, and bony bars which followed the pattern of the sulci. Faust (1931) thought that the cerebro-spinal fluid drained away through the spina bifida and allowed the cerebral pattern to become imprinted on the cranial bones. We have investigated all these theories and proved elsewhere that they are untenable. The analogy with 'thumbing' of the skull produced by cases of known raised intracranial pressure we have also shown to be fallacious. To the best of our knowledge both craniolacunia and craniofenestria are purely developmental anomalies similar to spina bifida, occurring usually in association with it, but also separately.

Because the cranial maldevelopments occur so much more frequently, because they can easily be diagnosed by radiological means, and because they

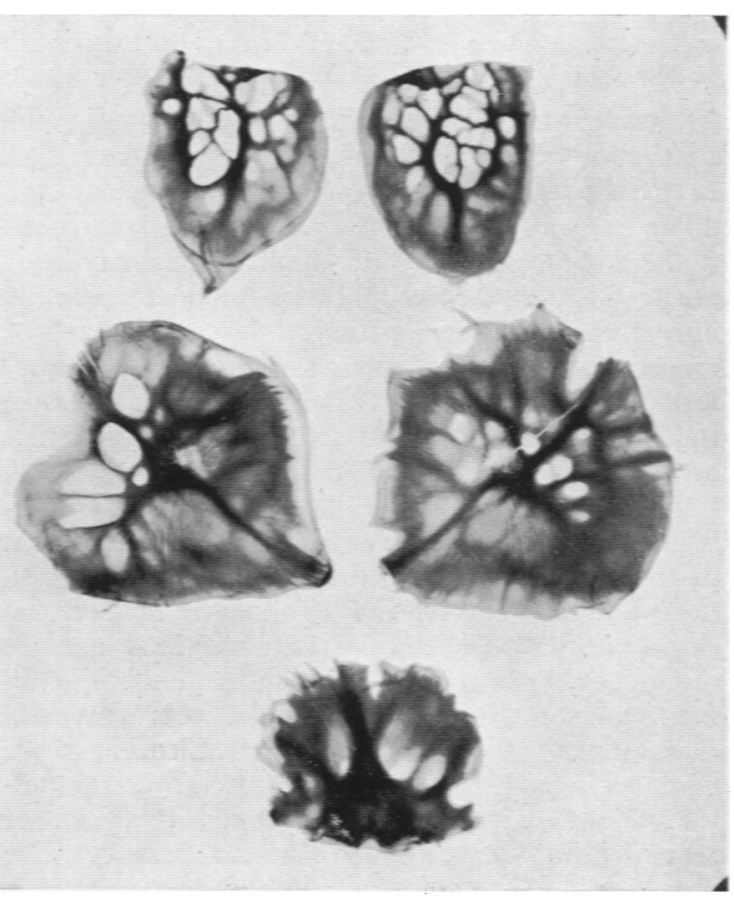

FIG. 6.-Radiographic appearances of craniofenestria. Note the increased density of the bars, and their sharp definition and relatively slight width as compared with those seen in craniolacunia. 


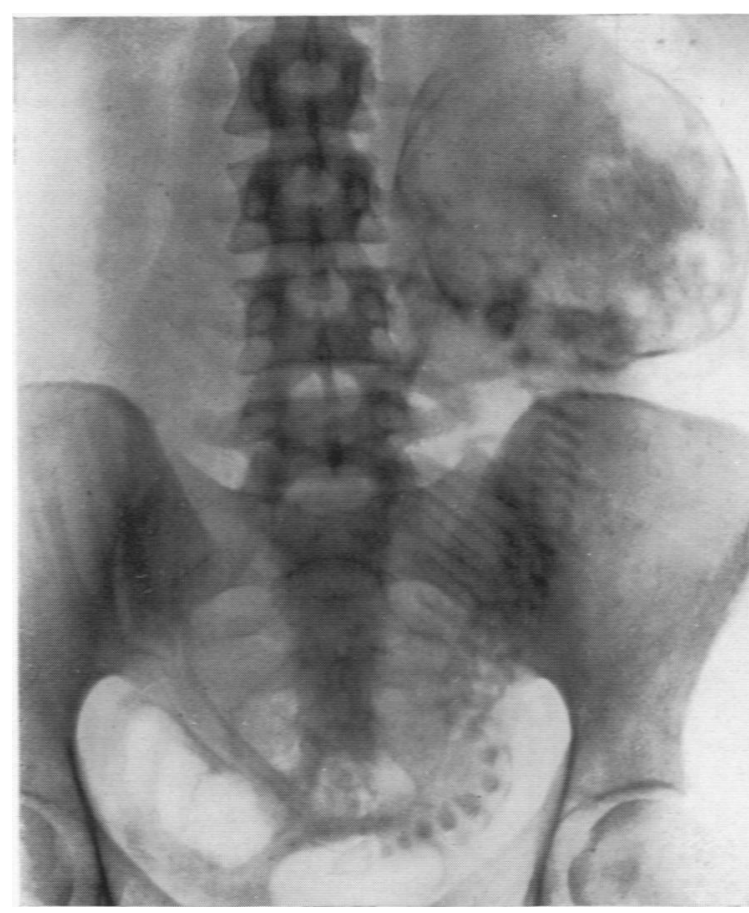

FIG. 7.-Antenatal radiograph in which the association of defective outline of the foetal vault bones with an obvious deformity of the spine enabled a confident diagnosis of craniolacunia plus spina bifida to be made before term.

are sometimes compatible with life, they offer bigger opportunities for research into their mode of production, and into the laws governing their familial transmission.

Thus in the family quoted by Butler-Smythe, it would have been of value to look for the presence of craniolacunia in the two hydrocephalic children, as well as in the three subjects of spina bifida. If the hydrocephalic reported alive at the age of two years lived to maturity and had offspring, the formation of their vault bones would be of extreme interest. Craniolacunia, moreover, offers better opportunities to study etiology, because, being diagnosable at or even before birth, it is feasible to obtain more complete data regarding the mother whilst she is in hospital. as well as to invite her collaboration during any future pregnancy. This should render it possible in the future to examine the possibility of, for example, a dietetic factor in the etiology.

The following suggestions are accordingly made:

1. That all cases of spina bifida should be $x$-rayed for evidence of craniolacunia or craniofenestria.

2. That skulls from all cases of twins should be examined radiologically if one or both show evidence of a congenital anomaly known to be associated with craniolacunia.

3. That skulls of parents and siblings of known cases of spina bifida should be examined in a similar manner.

4. That the offspring of known cases of craniolacunia should be closely watched for evidence of transmission of the condition.

5. Mothers of craniolacunar infants should be invited to collaborate with the obstetricians during any future pregnancy.

If in future the familial and hereditary incidence of craniolacunia is studied in this manner instead of the corresponding features of frank spina bifida it is believed that information will accumulate with greater rapidity and will lead to the elucidation of what has always been an obscure corner of medicine.

\section{Summary}

1. The incidence rate of the developmental anomalies of the vault bones of the foetal skull known as craniolacunia and craniofenestria is shown to be nearly 1 per cent. of all births.

2. Their frequent, and little known, association with spina bifida is emphasized.

3 . It is suggested that the laws governing the inheritance of spina bifida are more likely to be discovered by a study of the relatively common developmental defects, namely craniolacunia and craniofenestria (including study of the mothers of infants so affected, immediately and during any future pregnancy).

\section{Acknowledgement}

Thanks are due to the Editorial Committee of the British Journal of Radiology for permission to use the illustrations in this paper and for their courtesy in supplying the blocks from which they were made.

\section{REFERENCES}

Ballantyne, J. W. (1902). Manual of antenatal pathology and hygiene, Edinburgh.

Bland Sitton, J. (1888). Trans. path. Soc. Lond., 39, 432.

Butler-Smythe, A. C. (1889). Lancet, 1, 272.

Cumston, C. G. (1903). Clin. J., 22, 280.

Dareste, C. (1882). C. R. Acad. Sci., Paris, 94, 173.

Faust, H. (1931). Beitr. path. Anat., 86, 613.

Fry, A. (1943). Brit. med. J., 1, 131.

Good, J. P. (1910). Enquiry into causation of spina bifida, M.D. Thesis, Manchester.

Hartley, J. B., and Burnett, C. W. F. (1943a). J. Obstet. Ginaec., 50, 1 : (1943b) Brit. J. Radiol., 16, 99.

Kassowitz, M. (1880). Wien. med. Jb., 315.

Koch, W. (1881). Mittheilungen über Fragen der wissenschaftlichen Medicin, Part I, Kassel.

Lebedeff, A. I. (1881). Virchow's Arch., 86.

Mall, F. P. (1905). J. Morph., 19, 1.

Morgan, T. H., and Tsuda, U. (1894). Quart. J. micr. Sci., 35, 373.

Pybus, F. C. (1921). Lancet, 2, 599.

Richter, (1888). Verh. anat. Ges. Jena, 2, 159.

St. Hilaire, E. (1822). Philosophie Anatomique, 2, 131.

Von Recklinghausen, F. (1886). Virchow's Arch., 105, 243 and 373.

Wertheim, C. C. (1857). Mschr. Geburtsh. Gynäk., 9, 127.

West, J. F. (1875). Lancet, 2, 552. 